\title{
Wastewater suspended solids study by optical methods
}

\author{
N. Azema ${ }^{a}$, M.-F. Pouet ${ }^{b, *}$, C. Berho ${ }^{b}$, O. Thomas ${ }^{b}$ \\ ${ }^{a}$ Centre des Matériaux de Grande Diffusion, Ecole des Mines d'Alès 6, Avenue de Clavières, 30319 Alès, Cédex, France \\ ${ }^{\mathrm{b}}$ Laboratoire Génie de l'Environnement Industriel, Ecole des Mines d'Alès 6, Avenue de Clavières, 30319 Alès, Cédex, France
}

\begin{abstract}
The aim of the paper is to compare two optical methods (UV spectrophotometry and laser granulometry) for a better knowledge of the behaviour of wastewater suspended solids. The first one, based on UV spectrophotometry, is used for the estimation of solids concentration and nature in water and wastewater with the help of an advanced exploitation method of UV spectra. But the interpretation of UV spectra, in presence of a very wide size distribution of solids is not always easy, because of the different phenomena responsible of light diffusion. The second method, more classical, allows to characterise the size distribution of particles.
\end{abstract}

Keywords: Colloids; Particles; Characterisation; UV spectrophotometry; Laser granulometry

\section{Introduction}

Colloidal and particulate matter in wastewater have a great influence on performances of wastewater treatment plants. Each operation unit such as settling, biological or chemical treatment is concerned by phenomena of agglomeration or dispersion of colloids [1]. The importance of colloids is also primordial in adsorption and transportation of heavy metals or organic micropollutants [2]. Therefore, the understanding of these phenomena, the development of methods allowing the characterisation and the quantification of solids in sewage are necessary for the

\footnotetext{
* Corresponding author. Tel.: + 33-4-66-782728; fax: + 334-66-782701.

E-mail address: marie-florence.pouet@ema.fr (M.-F. Pouet).
}

optimisation of treatment processes and for the evaluation of their performances $[3,4]$.

Urban wastewater is a mixture of organic and mineral pollutants, the size distribution of which is very wide (Fig. 1). Four families of compounds are usually defined to describe the pollution fractions contained in urban wastewater, soluble $(<$ $0.001 \mu \mathrm{m})$, colloidal $(0.001-1 \mu \mathrm{m})$, supracolloidal $(1-100 \mu \mathrm{m})$ and settleable fractions $(>100 \mu \mathrm{m})$ [6]. Total Suspended Solids (TSS) are made up of supracolloids and settleable matter. Besides their physical properties (stability, settleability, ...), these fractions presenting a large heterogeneity have interesting optical properties.

Among the wastewater characterisation methods, UV spectrophotometry is a simple and fast method and has proved to be a valuable tool to monitor wastewater treatment and to estimate 


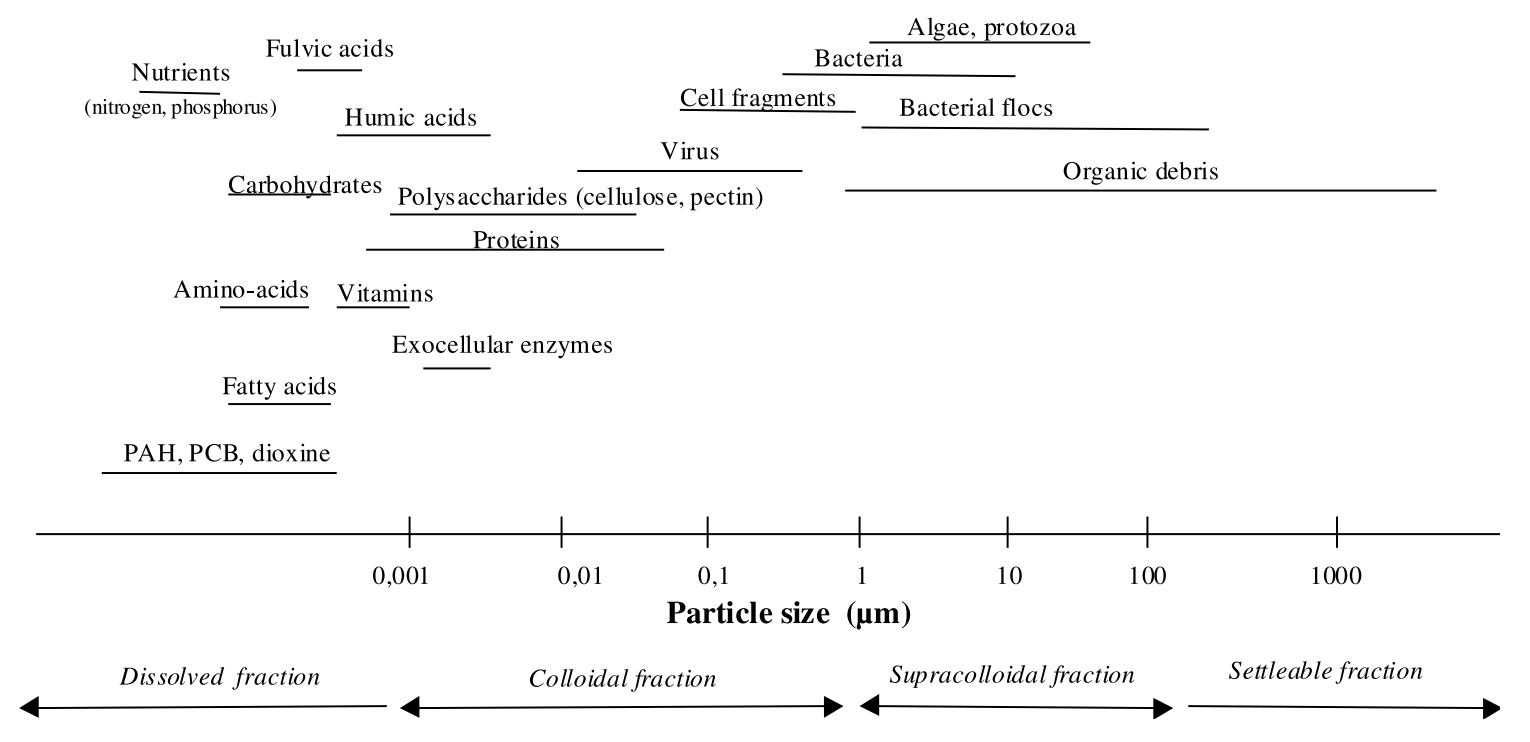

Fig. 1. Size distribution of contaminants in urban wastewater (adapted from [5]).

pollution parameters [7-9]. Nevertheless, the shape of UV spectra is not always related to the particles size distribution and the role of each fraction is not really defined [10].

Therefore, the aim of this work is to study the heterogeneous fractions of urban wastewater by two optical methods (UV spectrophotometry and laser granulometry) in order to have a better understanding of heterogeneous fractions. First, some theoretic elements on light diffusion by particles are presented. Then, the experimental procedure and the optical methods are explained. Finally, the limits of each method are tested and the influence of mechanical stirring is studied in order to see the interest of each technique for the characterisation of urban wastewater.

\section{Some elements on diffusion of light by particles}

When a particle is illuminated by a beam of light (Fig. 2), it sends back light in all directions of the space: it is the diffusion phenomenon whose three components are refraction, the reflection and diffraction [11]. In some case the light may be absorbed by particles. These inter- actions between a light beam and particles depends mainly on the ratio between the particle size (diameter $d$ ) and the wavelength $(\lambda)$ of the beam of light. In order to precise the domain of each phenomenon, a size parameter $\alpha$ has been defined:

$\alpha=\frac{\pi d}{\lambda}$

According to the value of the parameter $\alpha$, and with light sources usually used (UV, visible, near IR), three domains are considered:

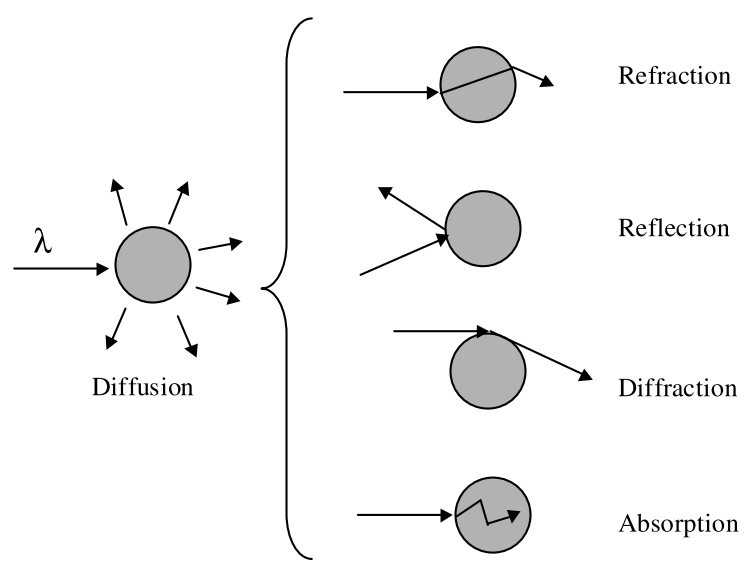

Fig. 2. Main mechanisms of light diffusion by particles. 


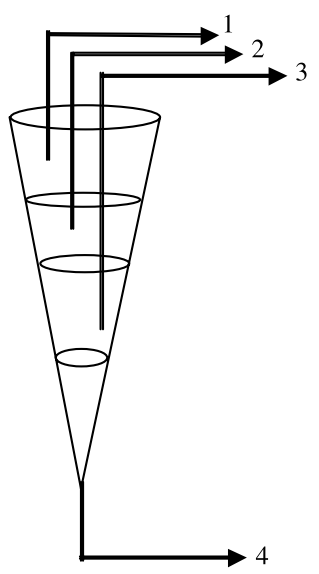

Fig. 3. Procedure of separation in Imhoff tank.

- Particles submicronics (greater than $1 \mu \mathrm{m}$ size) $(\alpha<0.3)$. For $\alpha<0.3$, the optical model of the Rayleigh diffusion is used. The particles diffuse light as much forward as backward.

- Particle size superior to several microns $(\alpha>$ $30)$. Laws of optical geometric and diffraction are used. In this case, the light is diffracted meaning that the diffusion is mainly concentrated in front of the particles.

- Micronic particles $(0.3<\alpha<30)$. This intermediate domain corresponds to the validity limit of the last models (diffusion and diffraction), because, diffusion is also influenced by reflection, refraction and absorption phenomena. These particles can be taken into account by the complex theory of Lorenz-Mie.

In conclusion, in presence of solid particles, the absorption observed (diffuse absorption) is an apparent absorption due to different phenomena, studied hereafter by the use of another optical method based on laser diffraction, the laser granulometry.

\section{Materials and methods}

\subsection{Samples}

Experiments have be carried out on composite samples. The sampler used is an ISCO 3710 . The samples are time proportional, taken after the grit chamber of the Ales treatment plant. This study has been carried out on different composite samples, and the results obtained can be considered as representative.

\subsection{Experimental procedure}

The device presented on Fig. 3 is used in order to separate four fractions with different particle sizes. A wastewater 1-h settling in an Imhoff tank (volume 11 ) leads to the separation of four fractions of $250 \mathrm{ml}$. The separation is so based on the Stokes law and depends both diameter and density of the particles.

\subsection{Laser granulometry}

Measurements of particle size distribution are performed with a LS230 Beckman Coulter laser granulometer. The volume of the analysis cell is $125 \mathrm{ml}$.

In the laser diffraction technology, the particle size distribution is determined on the basis of the scattering of monochromatic light with a wavelength of $750 \mathrm{~nm}$ transmitted through the suspension. The measurement of the diffraction pattern by particles is characteristic of particles size [12]. The Fraunhofer optical model computes the flux pattern into particle size distribution in the range of $0.4-2000 \mu \mathrm{m}$ of particle diameters.

Two experimental conditions are considered:

- first, the suspension is analysed, when the mechanical stirrer is stopped (this experimental condition is close to a simple UV absorptiometry),

- secondly, the same sample is mechanically stirred, constantly during the second analysis (it is the usual experimental condition).

\subsection{UV spectrophotometry}

For UV spectra acquisition, the spectrophotometer used is an Anthelie Light of Secomam of 2 $\mathrm{nm}$ bandwidth, with a quartz cell of $10 \mathrm{~mm}$ pathlength. The selected speed $\left(1800 \mathrm{~nm} \mathrm{mn}{ }^{-1}\right)$ is chosen with respect to the presence of suspended solids in samples. Exploitation of UV spectra (deconvolution method) is achieved with 
DATHEliE PC software (Secomam). Samples have been diluted by 5 .

The deconvolution method [9] decomposes the spectrum of a solution, the composition of which is unknown as a linear combination of reference spectra determined with a least square method. The absorbance can be then expressed as:

$A(\lambda)=\sum_{i=1}^{p} \alpha_{i} \times A_{i}(\lambda)+\sum_{j=1}^{q} \alpha_{j} \times A_{j}(\lambda)+e$

$p$, number of spectra of standard or known compounds; $A_{i}$, absorbance of the $i$ th reference spectrum of standard or known compound; $\alpha_{i}$, contribution coefficient of the $i$ th reference spectrum; $q$, number of 'real' spectra corresponding to size range fractions; $A_{j}$, absorbance of the $j$ th reference spectrum (size range fraction); $\alpha_{j}$, contribution coefficient of the $j$ th reference spectrum; $e$, restitution difference between real and restitued spectrum.

The base of reference used for this study is composed of spectra corresponding to suspended solids, colloids (matter whose size is comprised between 1 and $0.025 \mu \mathrm{m}$ ), soluble matter (containing finest colloids below $0.025 \mu \mathrm{m}$ ), nitrates and surfactants (DBS) (Fig. 4). With the deconvolution method, the value of aggregate parameters can be calculated but qualitative information is also available. In this work, values of each contribution coefficient explaining the UV spectrum have been studied.

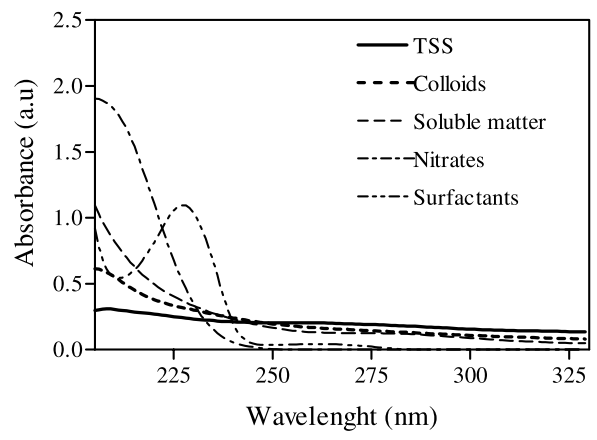

Fig. 4. Reference spectra of the basis used for domestic sewage samples [9].

\section{Results and discussion}

\subsection{Analysis of each fraction by the two optical methods}

\subsubsection{Granulometric and morphological characteristics of particles}

Fig. 5 presents the granulometric distribution in volume of each fraction. The analyses have been carried out, with the laser granulometer, without stirring, on the four fractions.

The granulometric analysis of fractions 1, 2, 3 clearly show that particles are mainly supracolloids between 1 and $100 \mu \mathrm{m}$ with a main mode value close to $30 \mu \mathrm{m}$. Fraction 4 (sampled at the low of the Imhoff cone) presents only a widest size range with particle size larger than $100 \mu \mathrm{m}$, and a multi-modal distribution. One can obviously observe that a settling of $1 \mathrm{~h}$ leads to the separation of settleable matter: indeed fractions 1-3 do not contain particles with size above 100 $\mu \mathrm{m}$ even if in the first fraction, some millimetric floating particles are present. Information about colloidal population are minimised, because of the volumetric distribution data with respect to surface distribution data (Fig. 11).

Optical observations (Fig. 6) show that particles may be made up of individual granular or fibrous particles, of micro-organisms, for diameters smaller than $100 \mu \mathrm{m}$. Beyond this value, the fibrous particles are agglomerated and can trap the others. The agglomerates can reach millimetric diameters. One can specify that solids of each fraction are mainly of organic nature (about $90-100 \%$ of volatile matter).

The laser diffraction is one of the most widely technique used for the measurement of the particles size in the range from 0.4 to $2000 \mu \mathrm{m}$. But, a physical limit of the Fraunhofer scattering theory, used for size calculation, exists when the particle diameter is in the range of sizes close to the wavelength of laser light, $\lambda$. The optical diffraction model are practically applied when the size parameter $\alpha$ is larger than 30 , value corresponding to a diameter of about 7 $\mu \mathrm{m}$.

For smaller values of diameter, the result can be appreciated with greater uncertainty, espe- 


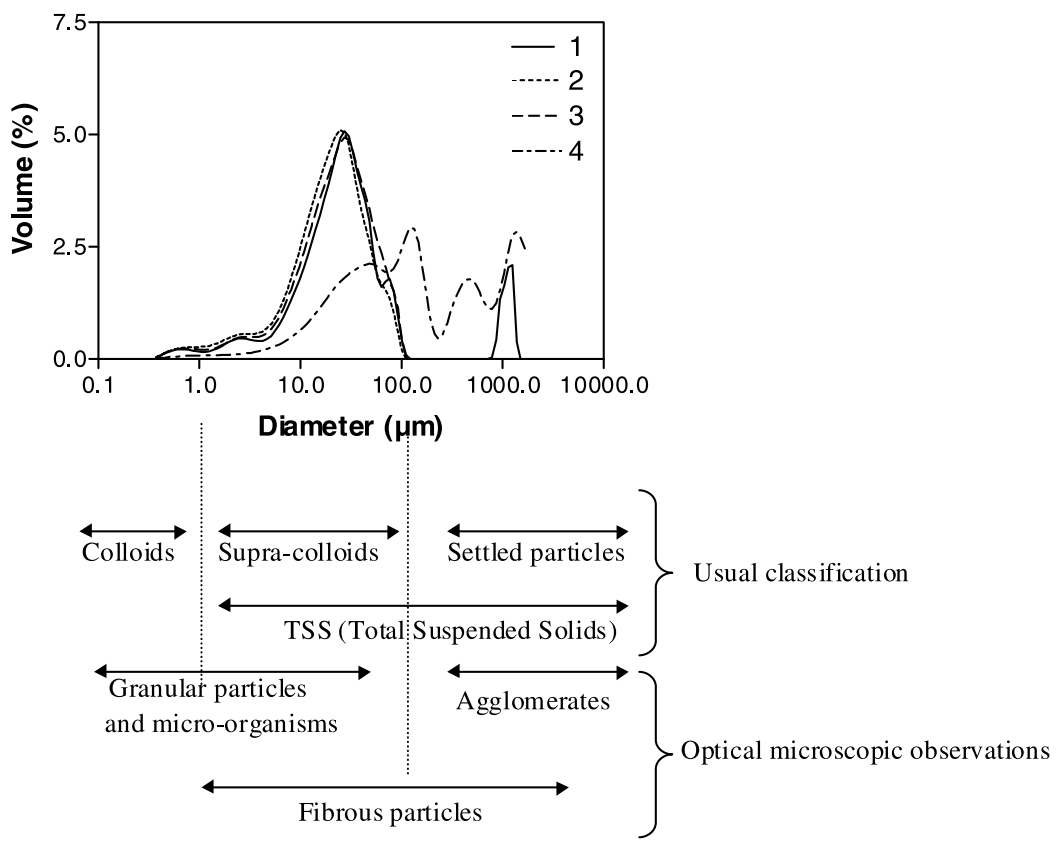

Fig. 5. Granulometric size distribution study of settled fractions urban wastewater samples.
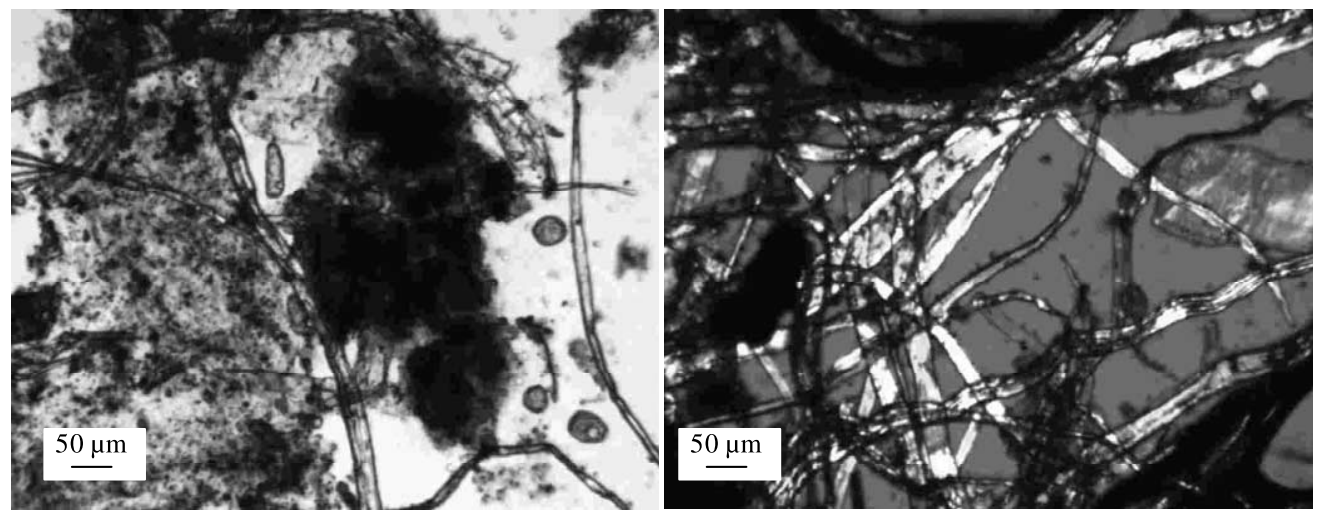

Fig. 6. Two optical observations of solids in wastewater.

cially when particles are transparent. In this last case, the refraction may play an important part and perturbs diffraction pattern. To check the existence of small particles (less than $7 \mu \mathrm{m}$ diameter), measurements are carried out with a photosedimentometer (Horiba-Capa 300), whose physical principle is based on Stokes law [13]. Fig. 7 represents three particle size distributions obtained by photosedimentometry: one in the range from 5 to $30 \mu \mathrm{m}$, and two in the range from 1 to $10 \mu \mathrm{m}$. The presence of particles in the range from 1 to $7 \mu \mathrm{m}$, confirms the validity of the measurement by laser diffraction in this range.

\subsubsection{Spectrophotometric results}

Fig. 8 presents the UV spectra of each fraction. The diffuse shape of UV spectra is due to both chemical and physical responses. For example, the shoulders observed at 225 and 270 


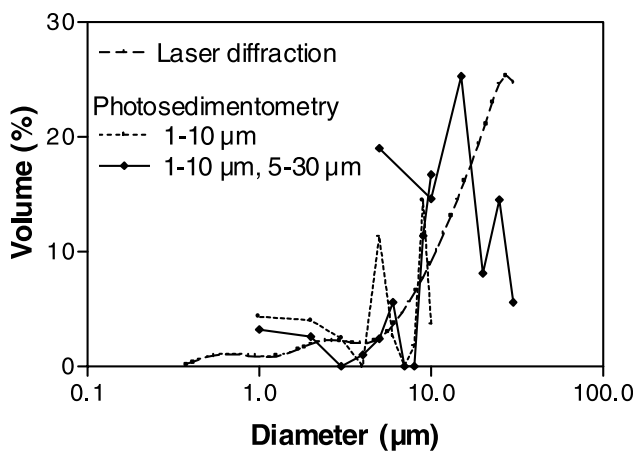

Fig. 7. Particle size distribution obtained by photosedimentometry of the fraction 1 .

$\mathrm{nm}$ are explained, respectively, by the presence of surfactants [14] and humic like substances.

The slope observed between 200 and $240 \mathrm{~nm}$ is mainly due to the presence of colloids and soluble matter: indeed it has been shown that the smaller the particles are, the higher the slope is [15]. UV spectrum of settleable matter is generally flat and a slight slope is observed if suspended solids are of organic nature.

Fig. 8a shows that UV spectra of the fractions 1, 2 and 3 are superposed, synonymous of a close composition, confirming the granulometric size distribution results. Fraction 4 presents a higher absorbance due to a high TSS concentration, without relation with the concentrations of other fractions. Indeed, whereas the three first fractions contain $100 \mathrm{mg}^{-1}$ and the fraction $4,670 \mathrm{mg}$ $1^{-1}$ of TSS, the corresponding contribution coefficients, calculated from Eq. (1) are 0.7 and 1, respectively. This is explained by the fact that

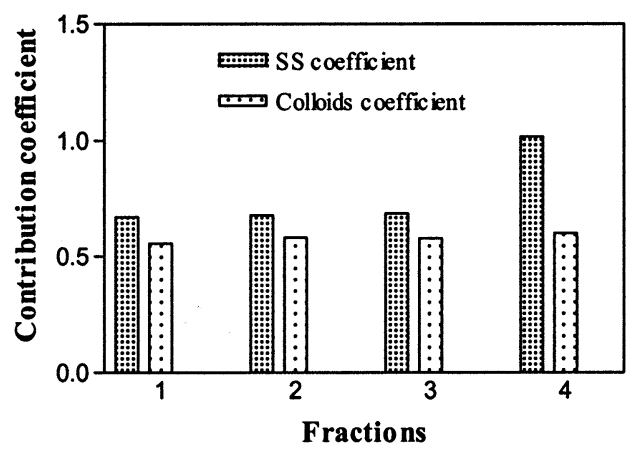

Fig. 9. Contribution coefficients (calculated from Eq. (1)).

settleable particles (whose size is above $100 \mu \mathrm{m}$ ) diffuse the light slightly. Thus the light diffusion by TSS is mainly due to the supracolloids. This important observation shows that a multivariate calibration should be envisaged if concentration of each fraction is needed. One can notice that the contribution coefficients, related to colloids, seems to be the same for the four fractions (Fig. 9).

The normalisation of the set of spectra (Fig. 8(b)) allows to compare the quality of each fraction. The presence of an isosbestic point revealed after normalisation points proves the water quality conservation between two mixtures that would be particulate matter and 'soluble' matter [10]. For the fraction 4, the slope break, around 240 $\mathrm{nm}$, is softened: this result confirms the presence of large particles [15]. Although it is not possible to discriminate supracolloids from settleable matter by UV spectrophotometry, the laser granulometry confirms the major role of supracolloids in the diffuse absorbance response.
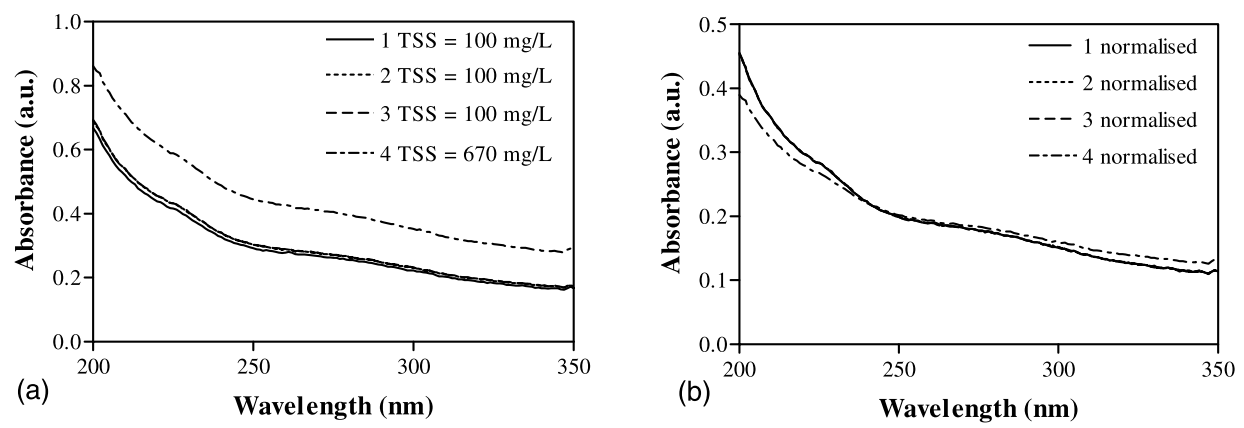

Fig. 8. UV spectra of each fraction (dilution 5) before (8a) and after normalisation (8b). 


\subsection{Study of the stability of suspensions}

Every fraction was analysed in a second time, with a mixing of the suspension provided by a mechanical stirrer. The size distributions and UV spectra have been acquired for the two experimental conditions (stirred or not stirred). As the influence of stirring on the fractions 1,2 and 3 is the same, the results concerning the fraction 3 are only presented.

\subsubsection{Granulometric size distribution results}

Results presented on Fig. 10 show that mechanical energy contribution does not involve the same modifications for all fractions. No influence on colloidal fraction is shown (Fig. 10 and Table 1). Indeed, the fraction 3 like the fractions 1 and 2 presents a decrease of the supra-colloids mode value (near $30 \mu \mathrm{m}$ ) and an increase of the percentage of larger supra-colloids and settled particles. Therefore, the mechanical energy applied leads to agglomeration phenomena. A singular point (point $\mathrm{T}$ ) can be observed on these two size distributions (stirred and not stirred), which corresponds to a crossing of the two curves.

To estimate the relationship between the disappearance of supra-colloid and the formation of settleable agglomerates, the difference of area curves before and after the point $\mathrm{T}$ was calculated. These values are negative or positive, respectively, for the disappearing or the formation of particles.

In Table 1, results clearly show for the fraction 3 (like for the fractions 1 and 2) that these phenomena correspond to a transfer of particle population from supra-colloid to settleable particles. The flocculation of supra-colloids is a known behaviour [16] in part due to the fibrous shape of particles.

For fraction 4, the suspension behaviour is inversed (Fig. 10(b)). Agglomerates whose diameter is larger than $100 \mu \mathrm{m}$ are dispersed in part and create supra-colloids. One can notice that the point $\mathrm{T}$ which position is $101 \mu \mathrm{m}$, corresponding
Fraction 3

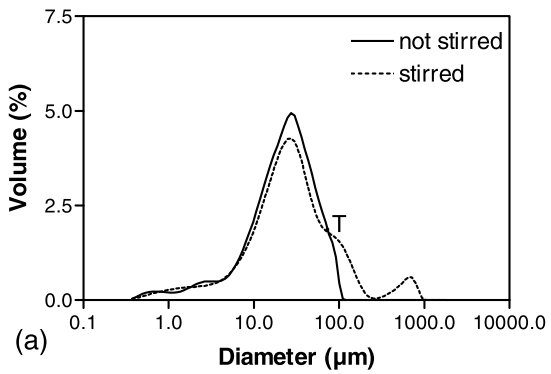

Fraction 4

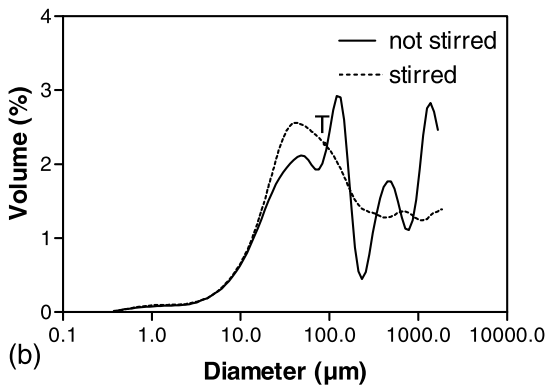

Fig. 10. Influence of stirring on granulometric size distribution of urban wastewater.

Table 1

Area evolution of particle size distribution according to the stirring

\begin{tabular}{|c|c|c|c|c|}
\hline Fractions & Areas $(\mu \mathrm{m})$ & Stirrer stop & Stirrer start & Difference \\
\hline \multirow[t]{4}{*}{3} & $<1$ & 2 & 2 & 0 \\
\hline & $<\mathrm{T}_{58}$ & 96 & 86 & -10 \\
\hline & $>\mathrm{T}_{58}$ & 13 & 24 & +11 \\
\hline & Total area & 109 & 110 & 1 \\
\hline \multirow[t]{4}{*}{4} & $<1$ & 1 & 1 & 0 \\
\hline & $<\mathrm{T}_{101}$ & 49 & 60 & +11 \\
\hline & $>\mathrm{T}_{101}$ & 57 & 47 & -10 \\
\hline & Total area & 106 & 107 & 1 \\
\hline
\end{tabular}


Fraction 3

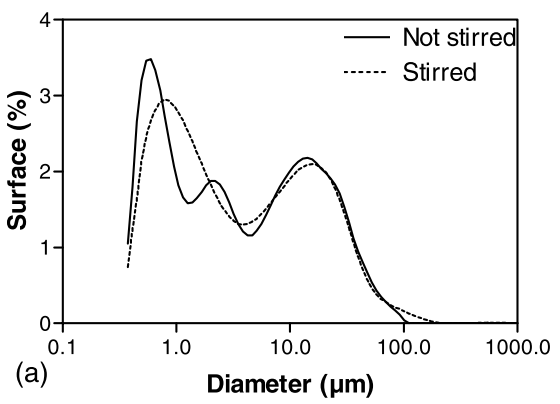

Fraction 4

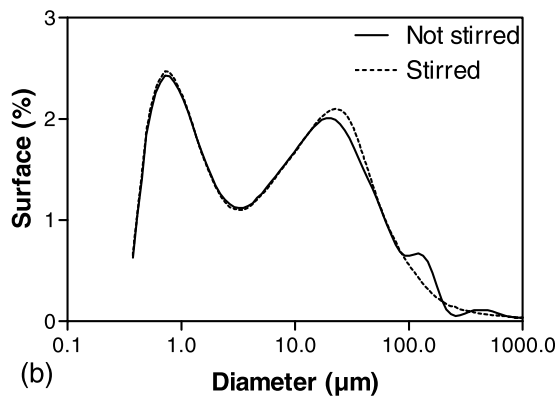

Fig. 11. Influence of stirring on granulometric size distribution of fractions 3 and 4 .
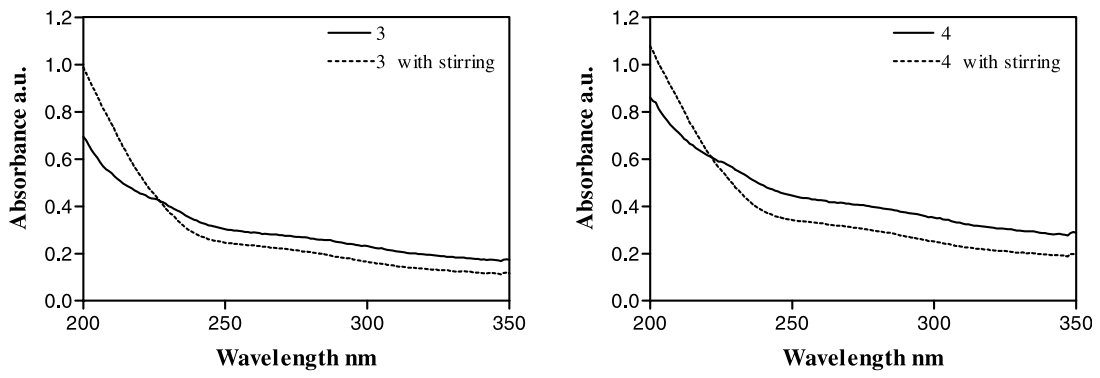

Fig. 12. Evolution of UV spectra with stirring of fractions 3 and 4.

to the frontier between supracolloidal and settable particles, defined by the usual classification. Values gathered in Table 1 show that variations of particle size appear in the same proportions, in all cases, but dispersion phenomena only occur in the fraction 4 . The use of the granulometric surface distribution (Fig. 11) allows a better presentation of the stirring influence on colloid particles. Indeed, it is well known that the smaller the particles, the higher the surface phenomena (for example pollutants adsorption).

Fig. 11 shows that, for fraction 3, stirring leads to an agglomeration of colloids (size below $1 \mu \mathrm{m}$ ) whereas for fraction 4 , no change is observed. The lowest concentration of colloids and the low sensibility of the technique in this size range can explain this last point. To sum up, according to granulometric results for fractions 1, 2 and 3, stirring leads to a decrease of colloids, and a transfer from supracolloidal to settleable particles. For fraction 4, stirring leads only to a dispersion of settleable particles.

\subsubsection{UV spectra exploitation}

Fig. 12 presents UV spectra before and after stirring. The mass conservation of the dry matter has been checked.

After stirring, UV spectra of all fractions present, on the one hand, a decrease of absorbance between 240 and $350 \mathrm{~nm}$ and on the other hand an increase of the slope between 200 and $240 \mathrm{~nm}$. The first observation proves that the stirring leads to the formation of larger particles by agglomeration, the second observation shows the dispersion of fine colloids. The role of agglomeration and dispersion, explaining the evolution of UV spectra are confirmed by the study of coefficient contribution. Fig. 13 shows both an increase of TSS coefficient and a decrease of large colloids coefficient $(1-0.025 \mu \mathrm{m})$, according to granulometric analysis (Fig. 11(a)). Moreover, an increase of 'soluble' coefficient (representing both soluble and fine colloids) is observed.

The transfer between each fraction explains the UV spectra evolution and confirms that heteroge- 


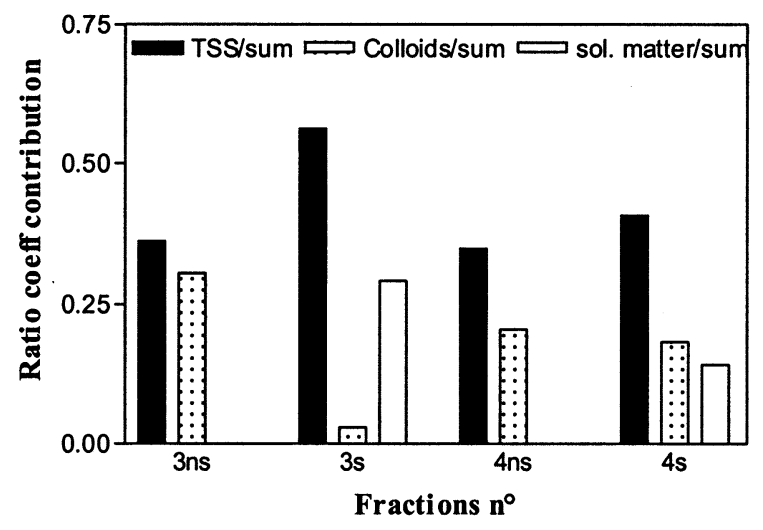

Fig. 13. Contribution coefficients evolution (ns, not stirred; s, stirred) of fractions 3 and 4 (calculated from Eq. (1)).

neous fractions are not stable as it has been demonstrated by granulometric analysis. This can explain partly the evolution of organic matter observed in sewers [17].

By comparing UV spectra to granulometric spectra for fractions 1,2 and 3 , it is possible to explain agglomeration, dispersion and solubilisation phenomena. The decrease of supracolloids (population around $30 \mu \mathrm{m}$ ) and large colloids can be explained both by the agglomeration of these particles and by the dispersion or solubilisation of colloids.

For fraction 4 , the results obtained by the two opticals methods are conflicting since the granulometric size distribution results show a decrease of large particles (settleable matter) and an increase of supracolloids (population of 30 $\mu \mathrm{m})$. Considering that TSS response is due mainly to surpacolloids (cf. Fig. 9), the phenomena observed by laser granulometry should result in an increase of UV absorbance. These differences of optical responses may be explained by high TSS concentration responsible for multiple diffusion [11] nature of organic debris, ....

\section{Conclusion}

The study of wastewater suspended solids by two optical methods has lead to a better under- standing of heterogeneous fractions thanks to the different fields of particles/light interactions of these two techniques. Laser granulometry allows a better discrimination of supracolloids and settleable particles although UV spectrophotometry provides more information mainly on soluble and colloidal fractions.

The complementarity of the two methods has also allowed to follow the dispersion, agglomeration and solubilisation phenomena. The particles stability depends on environmental conditions and characteristics of heterogeneous fractions as size, shape, organic or mineral nature, .... TSS concentration seems to be also an important parameter, but other factors, such as $\mathrm{pH}$ or conductivity, should also be considered.

\section{References}

[1] C.R. O’Melia, M.W. Hahn, C.T. Chen, Some effects of particle size in separation processes involving colloids, Water Science and Technology 36 (4) (1997) 119-126.

[2] L. Sigg, W. Stumm, P. et Behra, Chimie des milieux aquatiques. Chimie des eaux naturelles et des interfaces dans l'environnement, Masson, Paris, 1992.

[3] A.D. Levine, G. Tchobanoglous, T. Asano, Characterization of the size distribution of contaminants in wastewater: treatment and reuse implications, Journal of Water Pollution Control Federation 57 (7) (1985) 805816.

[4] U. Neis, A. Tiehm, Particle size analysis in primary and secondary waste water effluents, Water Science and Technology 36 (4) (1997) 151-158.

[5] A.D. Levine, G. Tchobanoglous, T. Asano, Size distributions of particulate contaminants in wastewater and their impact on treatability, Water Research 25 (8) (1991) 911-922.

[6] J.L. Balmat, Biochemical oxidation of various particulate fractions of sewage, Sewage and Industrial Wastes 29 (7) (1957) 757-761.

[7] N. Matsché, K. Stumwöhrer, UV absorption as controlparameter for biological treatment plants, Water Science and Technology 33 (12) (1996) 211-218.

[8] O. Thomas, F. Théraulaz, C. Agnel, S. Suryani, Advanced UV examination of wastewater, Environmental Technology 17 (1996) 251-261.

[9] O. Thomas, F. Théraulaz, M. Domeizel, C. Massiani, UV spectral deconvolution: a valuable tool for waste water quality determination, Environmental Technology 14 (12) (1993) 1187-1192.

[10] S. Vaillant, M.-F. Pouet, O. Thomas, Methodology for the characterisation of heterogenous fractions in wastewater, Talanta 50 (1999) 729-736. 
[11] A. Keitz, D. et Boulaud, Mesures et contrôle. Granulométrie des particules en mouvement et des aérosols, Techniques de l'Ingénieur R2 (360) (1995) 2/4.

[12] S. Röthele, U. Kesten, The application of laser diffraction technology. In: Proceeding Second World Congress of Particle Technology, Tokyo, Japan, pp. 19-22.

[13] T. Allen, Particle Size Measurement, fourth ed., Chapman and Hall, 1990.

[14] F. Théraulaz, L. Djellal, O. Thomas, Simple LAS determination in sewage using advanced UV spectrophotome- try, Tenside Surface Det. 33 (6) (1996) 447-451.

[15] S. Vaillant, M.-F. Pouet, O. Thomas, Basic handling of UV spectra for urban water quality monitoring, Urban Water (2002) In press.

[16] O. Thomas, C. Burgess, UV-Visible Spectrophotometry of Water and Wastewater, Elsevier, Amsterdam, 2001, p. 500 parution.

[17] W. Kaijun, G. Zeeman, G. Lettinga, Alteration in sewage characteristics upon aging, Water Science and Technology 31 (7) (1995) 191-200. 